\title{
WEBSITES DOS ARQUIVOS PÚBLICOS: FUNČÕES EXERCIDAS E RECURSOS DE COLABORAÇÃ̃O E INTERAÇÃO COM OS USUÁRIOS
}

\section{LOS SITIOS DE LOS ARCHIVOS PÚBLICOS: FUNCIONES EJERCIDAS Y RECURSOS COLABORATIVOS E INTERACTIVOS CON LOS USUARIOS}

\author{
Lyvia Archer - lyviaarcher@gmail.com \\ Arquivista pela Universidade Federal Fluminense, UFF, atuando no \\ Ministério da Saúde \\ Regina de Barros Cianconi - rcianconi@globo.com \\ Doutora em Ciência da Informação \\ Professora Adjunta no Departamento de Ciência da Informação da \\ Universidade Federal Fluminense, UFF
}

\begin{abstract}
Resumo
Estudo realizado em sites de arquivos públicos brasileiros e estrangeiros, analisando o uso de recursos da Internet para executar diversas funções como busca por informação, acesso às coleções, e suporte aos usuários por meio de ferramentas de comunicação e colaboração, inclusive as ferramentas web 2.0, que dinamizam a participação dos usuários por meio de um ambiente interativo e colaborativo. Através de análise qualitativa dos websites de instituições arquivísticas, procurou-se identificar os recursos disponíveis para execução das funções exercidas pelos arquivos, em especial aqueles voltados à comunicação e colaboração on-line e que podem melhorar a eficiência dos serviços prestados aos usuários. Dentro desse contexto, aponta os benefícios em potencial do uso dos recursos colaborativos e interativos no relacionamento com o usuário, trazendo à tona a necessidade de acompanhamento tecnológico por parte das instituições arquivística, tendo como objetivo ampliar o relacionamento com seus usuários, a colaboração e acesso aos acervos via Internet. Ao apresentar os websites estrangeiros que utilizam grande parte dos recursos colaborativos, este estudo visa apontar a viabilidade e a funcionalidade do uso desses recursos nos websites de instituições arquivísticas.
\end{abstract}

\section{Palavras-chave}

Web Sites. Arquivos Públicos. Recursos informacionais. 


\section{INTRODUÇÃO}

A evolução das tecnologias da informação e comunicação causa impacto em todos os níveis da atividade humana e traz inovação constante aos canais e instrumentos de comunicação. Um importante canal é a Internet, um espaço de desenvolvimento da inteligência coletiva (LÉVY, 1998), sendo caracterizada pela interatividade, que atualmente ocorre por meio de comunidades virtuais, fóruns, blogs e wikis para construir e disseminar informações e compartilhar conhecimento.

O website é um meio de comunicação e de trocas das instituições com seus públicos e demais organizações, um espaço que anteriormente era visto como algo estático, um canal de via única da comunicação instituição-usuário. Contudo, essa visão vem se modificando com a exploração dos novos recursos tecnológicos que surgem continuamente, como as ferramentas interativas e colaborativas conhecidas como web 2.0 ou mídias sociais, que possibilitam aos usuários dialogar e trocar informações, desde opiniões a arquivos, como: textos, fotos, vídeos, músicas, etc.. Com os recursos de colaboração, os canais de comunicação passam a ser de "muitos-para-muitos", havendo diálogo entre usuário e a instituição e entre os próprios usuários - que colaboram entre si. Esses recursos estão presentes em: blogs, redes sociais como Orkut e Facebook, em mensagens instantâneas, em wikis e em sites de compartilhamento de arquivos como You Tube e Flickr.

Um dos papéis das instituições arquivísticas é disponibilizar acesso eficiente às informações contidas em seus acervos e atender às demandas de usuários. Esses novos recursos da web instigam mudanças nas perspectivas e práticas das instituições arquivísticas, além de trazerem alternativas para a disseminação da informação. Negroponte (1995, tradução nossa) afirma que vivemos em um mundo que se tornou digital, e há a necessidade das instituições acompanharem as evoluções tecnológicas, a fim de melhor atender seus usuários.

Lemos (2002 apud CORRÊA, 2004), enfatiza que o ponto de partida para a compreensão do comportamento social que marca uma determinada época é a consciência de que existe uma relação simbiótica entre a natureza, o homem e a sociedade, sendo que em cada período da história da humanidade prevalece uma cultura técnica particular.

A cultura contemporânea caracteriza-se pela ampliação no uso de tecnologias digitais, proporcionando o surgimento de novas formas de agregação social de maneira espontânea no ambiente virtual, com práticas culturais específicas, constituindo a chamada cibercultura. Segundo Lévy (1998, p.11), "o atual curso dos acontecimentos converge para a constituição de um novo meio de comunicação, de pensamento e de trabalho para as sociedades humanas".

Cabe às instituições arquivísticas, frente a essas transformações, buscar o aperfeiçoamento de suas funções, levando em conta que o acesso à informação e o relacionamento com os usuários são as mais atingidas pelos novos recursos de comunicação e colaboração.

Assim, foi realizado estudo com foco nas instituições arquivísticas públicas, buscando identificar os recursos disponíveis em seus websites para execução das 
funções exercidas pelos arquivos, em especial aqueles voltados à comunicação e colaboração on-line e que podem contribuir para a eficácia dos serviços prestados aos usuários. A análise do potencial de uso dos recursos colaborativos e interativos no relacionamento com o usuário, traz à tona os benefícios e a necessidade da utilização de tais recursos no contexto dos arquivos.

\section{ACESSO ÀS INFORMAÇÕES ARQUIVÍSTICAS}

A evolução tecnológica muda a concepção das instituições arquivísticas em vários aspectos. Neste novo cenário os usuários figuram ativamente, sendo necessário que seja reconhecida a pluralidade de suas necessidades de informação, analisadas com uma abordagem flexível, capaz de responder às demandas (OLIVEIRA, 2006, p.7)

Segundo Jardim e Fonseca (2004) a nova realidade do uso das tecnologias da informação e da comunicação configura alguns aspectos emblemáticos, tais como:

- O conceito de "lugar" passa a não ser o mais importante para o profissional arquivista e seus usuários;

- A importância do acesso à informação, se sobrepõe a da localização de onde a informação se encontra;

- A ênfase na gestão da informação é transferida do acervo para o acesso, do estoque para o fluxo da informação, e dos sistemas para as redes;

- Novas vocações são adquiridas por instituições (arquivos, bibliotecas, centros de documentação), além de renovarem novas funções e superarem outras;

- Através da popularização do uso das tecnologias informacionais, os usuários produzem novas demandas a instituições como arquivos, bibliotecas e centros de documentação e provocam a realocação ou anulação de fronteiras que demarcam esses espaços;

- Há o surgimento de espaços informacionais virtuais como parte dessas instituições, o que sugere novas possibilidades de gestão da informação.

Lidar com o grande fluxo informacional produzido e, ao mesmo tempo, manter seus usuários cientes da existência dessas informações, tem sido um grande desafio enfrentado tanto pelas instituições arquivísticas, quanto pelos seus usuários.

A inclusão da tecnologia web no cotidiano dos usuários e também nas atividades de prestação de serviços dos arquivos produz novos fluxos e novos usos de informação. Identificar necessidades, especificar e implantar recursos que tornem as informações que transitam nesses fluxos mais acessíveis aos usuários, é a uma das finalidades do trabalho arquivístico contemporâneo.

Frente às crescentes demandas dos usuários, e com a finalidade de operacionalizar uma das recomendações da Mesa Redonda Nacional de Arquivos, realizada em 1999, foram elaboradas por uma Comissão Especial designada pelo Conselho Nacional de Arquivos (2000): as Diretrizes Gerais para 
a construção de websites de Instituições Arquivísticas, com o objetivo de orientar os gestores dessas instituições no desenvolvimento de seus websites. Contudo, há uma grande obsolescência com relação às possibilidades atuais da tecnologia, apesar do documento tratar o website de uma instituição arquivística como um instrumento de prestação de serviços dinâmico e atualizável e abordar a necessidade de redefinição das formas de relacionamento com seus usuários presenciais, e criação de vínculo com os usuários virtuais. A utilização dos recursos de mídias sociais como parte desse canal de diálogo não é citada, pois são tecnologias que se tornaram populares recentemente, no início do século XXI. Entretanto, apesar das diretrizes não tratarem explicitamente dos recursos 2.0, estes vem sendo utilizados em instituições voltadas a prover acesso e disseminar informação, como as bibliotecas e os arquivos, sendo relevante, portanto, identificar seus possíveis usos, de modo a incorporá-los a serviços que possam ser oferecidos pela Internet.

Deste modo, é mister que as instituições arquivísticas e seus profissionais adquiriram e ampliem suas competências a fim de explorar recursos da Internet, tendo como foco ampliar o acesso às informações arquivísticas a todos os seus usuários e permitir colaboração entre eles e com as instituições arquivísticas.

\section{RECURSOS DA WEB TRADICIONAL (WEB 1.0) E DA WEB SOCIAL (WEB 2.0)}

A Internet possui diversas ferramentas on-line que podem contribuir para o melhor atendimento e aumento do número de usuários, proporcionando uma maior visibilidade institucional aos arquivos, renovando-os e adequando sua missão à nova realidade das redes. De acordo com Jardim (2002 apud MARIZ, 2005), a produção e gestão de um website torna-se objeto de uma das estratégias potencialmente mais eficazes de difusão dos arquivos, favorecendo a diferentes tipos de uso e usuários, ao acesso às informações sobre a instituição, sobre seus serviços e acervo.

Os recursos tradicionais da web e os recursos de colaboração e interação que se encontram atualmente disponíveis, destacados a seguir, podem auxiliar no cotidiano dos arquivos públicos.

O termo web 1.0 é utilizado para diferenciar as duas gerações da web. A primeira geração tem como principal característica um modo mais "estático", pois a web, em seus primórdios, na década de 1990, era entendida como uma vitrine (CASTELLS, 1999) por meio da qual as organizações expunham seus objetivos, meios de contato; a troca de informações e conteúdos era realizada na forma "um-para-um" ou "um-para-muitos", ou seja, de usuário para usuário, de usuário para instituição ou de instituição para usuários. Apesar de mais "antigos", nem todos os seus recursos estão obsoletos e muitos são utilizados até os dias de hoje. A web incorpora as ferramentas tradicionais e as novas. Exemplos dos recursos da web 1.0 ainda em uso são:

Correio Eletrônico (e-mail) - permite que usuários situados em lugares distintos troquem mensagens, quebrando barreiras geográficas. Os sites das organizações, em sua maioria, apresentam além de endereço físico, um e-mail 
para contato, ou um link do tipo "Fale Conosco" onde é apresentado um formulário on-line que auxilia na filtragem das mensagens, permitindo enviá-las diretamente aos respectivos interessados.

Mensagens Instantâneas - um tipo de bate-papo (do inglês "chat"), é um recurso que permite o envio e recebimento de mensagens de texto em tempo real, como também de arquivos de foto, texto, imagem, etc., além de possibilitar conferências em áudio, e até audio-visuais. Através das mensagens instantâneas, o usuário tira suas dúvidas on-line e obtém retorno imediato, sem ter que aguardar um contato via e-mail.

Questões Freqüentes (FAQ's) ${ }^{1}$ - são conjuntos de perguntas e respostas relativas a dúvidas apresentadas por usuários. O benefício deste recurso é o esclarecimento ao usuário, agilizando o atendimento.

Videoconferência - permite o contato visual e sonoro entre pessoas que estão em lugares diferentes, em tempo real. Pode ser utilizada para ministrar cursos, apresentar tutoriais, seminários on-line.

A chamada web social, também descrita na literatura como mídias sociais ou web 2.0, embora tenha uma conotação que faz pensar em uma nova versão para a web - na verdade não se refere somente a uma atualização em sua tecnologia, mas principalmente a uma mudança no modo como ela é encarada e usada pelos usuários, ou seja, trata-se de um ambiente de interação e colaboração que engloba inúmeras facilidades e motivações para a participação dos usuários e troca de experiências e opiniões.

O termo web 2.0 foi cunhado em 2004, durante uma conferência promovida pelas empresas de mídia, em São Francisco, nos Estados Unidos, MediaLive e O'Reilly Media, onde foi discutida a necessidade da web ser mais dinâmica e interativa, permitindo aos internautas colaborarem com a criação de conteúdos (MANESS, 2007).

Neste início do século $\mathrm{XXI}$, as mídias sociais ganham grande popularidade e trazem contribuições importantes para a sociedade, sendo capazes de potencializar as formas de publicação, compartilhamento e organização de informações, além de aumentar as possibilidades de interação e colaboração entre os usuários.

A liberdade de comunicação interativa, combinada à facilidade de uso das ferramentas, somada a uma arquitetura participativa em redes, forma a base da inserção das mídias sociais no cotidiano dos usuários.

Alguns exemplos de recursos da web 2.0 facilitadores dessa interação e colaboração que podem ser utilizados em sites de arquivos são:

Blogs - uma espécie de diário virtual. É a abreviação da palavra weblog: web (teia), termo utilizado para designar o ambiente virtual em rede - e log (registro). Nos blogs, os textos são chamados posts, podem conter imagens, sons ou vídeos e são organizados cronologicamente. Por meio de comentários (comments) os usuários dão suas opiniões sobre um post, sobre o blog, ou mesmo sobre o proprietário do blog. As instituições arquivísticas encontram nesse

\footnotetext{
${ }^{1} \mathrm{FAQ}$ - sigla derivada da expressão "Frequently Asked Questions",
} 
recurso um meio potencial de estreitar o relacionamento com seus usuários. No blog, o usuário pode expor suas necessidades e insatisfações, colaborar para melhorar a qualidade dos serviços prestados e auxiliar outros usuários com comentários, opiniões, sugestões.

Microblogging - surgiu em 2006, e tem sido popularizado por seu pioneiro: - Twitter, que é uma rede social que permite aos usuários o envio e a leitura de atualizações pessoais através da própria web ou por SMS (mensagens instantâneas recebidas através do celular). Os post, que têm no máximo 140 caracteres, são chamados de "tweets". As atualizações são exibidas em tempo real no perfil do usuário, que é a página Twitter pessoal onde o usuário digita seus tweets e vê os comentários e post de seus seguidores, ou seja, usuários do Twitter que optam em ter um link direto para Twitters de terceiros. Também podem ser enviadas a usuários que tenham autorizado seu recebimento por meio das ferramentas de Feed (RSS). As instituições vem usando o Twitter para comunicação rápida e divulgação de novidades aos usuários.

RSS - é a sigla em inglês para Rich Site Summary ou Really Simple Syndication, que é uma forma simplificada de informar ao usuário que uma página web foi atualizada, um recurso que permite aos usuários se inscreverem em sites que fornecem feeds. RSS são ferramentas de agregação de conteúdos (feeds), que correspondem aos endereços eletrônicos que são relacionados à ferramenta de leitura usada pelo usuário. Útil para páginas com conteúdo atualizado frequentemente, como notícias ou blogs. Os usuários podem permanecer informados sobre as atualizações nos sites escolhidos, sem precisar visitá-los. As organizações vêm fazendo uso deste recurso para enviar notícias e alertas a seus clientes e/ou usuários, sendo aplicável às instituições arquivísticas.

Wiki - criado em 1995, é um tipo de site no qual os usuários tem a permissão de gerar, gerenciar e disseminar conteúdos. É como uma coleção livre e expansível de páginas web interligadas por um sistema de hipertexto, que permite criar, e modificar os conteúdos, com facilidade através do navegador (browser). Um diferencial do wiki é o fato do conteúdo poder ser editado e atualizado pelos usuários a qualquer momento, sem a necessidade de autorização do autor da versão anterior (BLATTMANN; SILVA, 2007, p. 202). É um sistema que permite correção de erros e inserção de novas informações em um ambiente onde não há um autor proprietário do texto, e sim uma produção de conteúdos participativa e colaborativa. Nas instituições arquivísticas, os wiki podem atuar, por exemplo, na geração colaborativa de conteúdo de interesse dos usuários.

Etiquetas (Tags) - recurso utilizado pelos usuários para classificação de conteúdos na web. São palavras-chaves consideradas relevantes associadas a uma informação, permitindo uma indexação de assuntos com tags atribuídas pelos usuários. São escolhidas informalmente e com critério pessoal do usuárioautor do item de conteúdo, não constituindo um esquema formal de indexação. Permitem que o usuário organize a informação através de sua própria visão, descentralizadamente, em contraste com uma taxonomia elaborada pelos gestores de conteúdo, de forma centralizada. Esta ferramenta possui um recurso agregador, que agrupa conteúdos marcados com as mesmas tags por diferentes usuários, criando uma classificação coletiva, de forma tal que as tags mais 
utilizadas se destacam, seja pelo tamanho da fonte na chamada "nuvem de tags" seja pelo indicativo numérico de quantas vezes cada tag foi associada a um documento ou à página em questão.

Marcadores de Favoritos (Social Bookmarking) - também conhecido como favoritos compartilhados, é uma ferramenta capaz de armazenar, classificar, compartilhar e pesquisar links que apontam para endereços de websites. Ao invés de armazenar links no computador do usuário, este recurso permite este armazenamento em um servidor remoto. São utilizadas etiquetas (tags) para a classificação dos links, que podem ser visualizados por outros usuários. Um dos exemplos mais populares de Social Bookmarking é o Del.icio.us.

Redes Sociais - permitem aos usuários fazerem links para pessoas que eles conheçam, podendo compartilhar informações com essas pessoas. Os usuários compartilham informações, fotos e podem utilizar o sistema público ou privado para enviar mensagens uns aos outros. Exemplos populares dessa ferramenta são: Facebook, MySpace, LinkedIn e Orkut. Estes serviços estão sendo utilizados também por instituições como um ambiente de contato com seus usuários, criando e administrando comunidades, que são ambientes onde é possível debater através de fóruns, fazer enquetes com seus usuários, enfim, interagir com eles, estar ciente de suas insatisfações e sugestões. Alguns arquivos públicos já utilizam esse recurso, como o Arquivo Nacional, Arquivo Público de Campos, do Pará, Mineiro, do Estado de São Paulo, do Espírito Santo, do Piauí, do Amapá, do Rio Grande do Sul, do Paraná, da Bahia, de Canoas e do Ceará.

Mashups - são recursos combinados, possibilitando que partes da tecnologia de um programa sejam utilizadas em outros, constituindo assim um novo recurso.

Sites de hospedagem e compartilhamento de arquivos da web 2.0 - são recursos externos ao website das organizações. No caso de arquivos públicos, são úteis pois não demandam utilização de espaço nos computadores das instituições arquivísticas, são gratuitos em sua maioria, e demandam pouco ou nenhum treinamento, pois, em geral, são conhecidos pelos usuários da web.

Um dos mais utilizados é o Flickr, um site que permite o compartilhamento de documentos gráficos (desenhos, fotografias, etc). Permite aos usuários a criação de álbuns para armazenamento de fotografias e utiliza o sistema de categorização por meio de etiquetas (tags).

Outro exemplo é o YouTube, um site que permite o carregamento e o compartilhamento de vídeos em formato digital. Hospeda uma grande variedade de filmes, videoclipes e materiais caseiros e/ou profissionais. O material encontrado no YouTube pode ser disponibilizado em blogs e sites, através de mecanismos que permitem "embutir" os conteúdos de um site em outro. Estes mecanismos podem ser utilizados por instituições e empresas a fim de divulgar seus serviços, eventos, etc.

Essa possibilidade de armazenar todo tipo de conteúdo produzido pelos usuários, além dos próprios sistemas operacionais, em servidores de computadores on-line é chamada de computação na nuvem (cloud computing). Através dessa facilidade torna-se desnecessária a instalação de dispositivos de 
armazenamento no computador do usuário, e há a possibilidade de compartilhamento de conteúdos com qualquer plataforma de acesso à web.

Alguns fatores são importantes para a adaptação dos usuários aos recursos web 2.0: estes devem confiar nos colaboradores, entendendo que a participação eficaz e o envolvimento dos usuários ocorrem quando a interação é feita de modo espontâneo, e não por obrigação, e este envolvimento deve ser feito através de um espaço de troca de informações, experiências e idéias (CUNNINGHAM, 2006).

\section{EXEMPLOS A SEREM SEGUIDOS}

No campo da Ciência da Informação, a Biblioteconomia apresenta uma razoável quantidade de discussões a respeito da relação das bibliotecas e seus usuários com os recursos da web 2.0. O uso e aplicação dos recursos colaborativos e interativos vem representando uma significativa mudança nos serviços das bibliotecas, tornando-as mais interativas e acessíveis. Tornam-se o lugar onde os usuários podem não apenas procurar por material bibliográfico, mas interagir com diferentes comunidades e com os bibliotecários, compartilhando experiências e informações.

Outro fator importante a se levar em consideração na web 2.0 é a evolução tecnológica. Sabe-se que a web continuará a mudar rapidamente e que a web 2.0 é somente uma das muitas transformações que estão por vir. E tanto as bibliotecas como os arquivos devem se adaptar a ela, e às imprevisíveis mudanças futuras, assim como se adaptaram à web originalmente. Segundo O'Reilly ${ }^{2}$ (2005 apud MANESS, 2007) a única estabilidade na atualidade é a aceitação de instabilidade permanente, a web vive um "Beta perpétuo", e isto vale também para os Arquivos.

Um exemplo significativo do uso das ferramentas 2.0 nos sites das bibliotecas é o site da Library of Congress dos Estados Unidos da América que utiliza, entre outros recursos, o Flickr para divulgar imagens digitais de seu acervo, convidando seus usuários a comentar, utilizar etiquetas (tags), e auxiliar na identificação de fotos antigas que chegaram à biblioteca com descrição incompleta ou insuficiente.

Já no Brasil, um exemplo é a Divisão de Bibliotecas e Documentação da Pontifícia Universidade Católica do Rio de Janeiro - PUC-Rio, que adotou em 2009 o blog e o Twitter como meios de comunicação com seus usuários. Outro exemplo é o blog da biblioteca da Universidade do Vale do Rio dos Sinos UNISINOS, de São Leopoldo, no Rio Grande do Sul. Estes exemplos demonstram a vontade das bibliotecas de se manterem atualizadas e mais perto de seus usuários.

\footnotetext{
${ }^{2}$ Disponível em: <http://www.oreilly.com/go/web2>.
} 
Os museus também tem buscado se posicionar frente às tecnologias da Internet. $\mathrm{Na}$ web são encontrados diversos blogs de museus, como o Museu Medieval Castelo Saint George em Gramado (RS). Outro blog, bem elaborado é o do Museu da TAM, que também tem compartilhamento com Facebook, Yahoo, Google, entre outros; além de ter fotos no Flickr.

Esses exemplos deixam claro que a necessidade de acompanhamento da evolução tecnológica e comportamental da sociedade, no âmbito da Internet, por parte das organizações, vem sendo percebida por instituições como bibliotecas e museus. Mas, e as instituições arquivísticas?

\section{$5 \quad$ OS SITES DOS ARQUIVOS PÚBLICOS}

Com objetivo de traçar um perfil de como as instituições arquivísticas estão aproveitando essas ferramentas da web, foi desenvolvido este estudo. A partir de pesquisa na Internet foram selecionados sete sites de arquivos públicos brasileiros no âmbito municipal (Arquivo Geral da Cidade do Rio de Janeiro, RJ, Arquivo Histórico Municipal Professor Oswaldo Rodrigues Cabral, Florianópolis, SC, Arquivo Histórico Municipal Washington Luis, São Paulo, SP, Arquivo Municipal Olimpio Michael Gonzaga, Paracatu, MG, Arquivo Público de Uberaba, MG), seis da esfera estadual (Arquivo Público Mineiro, Arquivo do Estado de São Paulo, Arquivo Público do Espírito Santo, Arquivo Público do Paraná, Arquivo Público do Estado do Rio de Janeiro, Arquivo Público do Estado do Rio Grande do Sul), e um nacional (Arquivo Nacional), totalizando 14 sites que atendiam ao requisito de possuir presença na Internet. Participaram também desta análise três sites de arquivos públicos internacionais que apresentam características de compartilhamento e colaboração, um nos Estados Unidos (National Archives and Records Management), um no Canadá (Library and Arhives Canadá), e outro no Reino Unido (The National Archives) A análise dos sites foi realizada em duas etapas: a primeira por meio da identificação de recursos nos sites de arquivos e a segunda por meio de questionários, estes enviados somente aos gestores dos arquivos brasileiros.

À luz das funções informacional, referencial, pesquisa, instrucional, comunicação, propostas por Amaral (2005), e da função colaboração, que embora não esteja presente na literatura de avaliação consultada, foi acrescentada no instrumento de pesquisa, foi realizada a análise dos sites de arquivos públicos identificados:

Função informacional - informações sobre a instituição, sua história, missão localização etc., conforme demonstrado no Gráfico 1, a seguir:

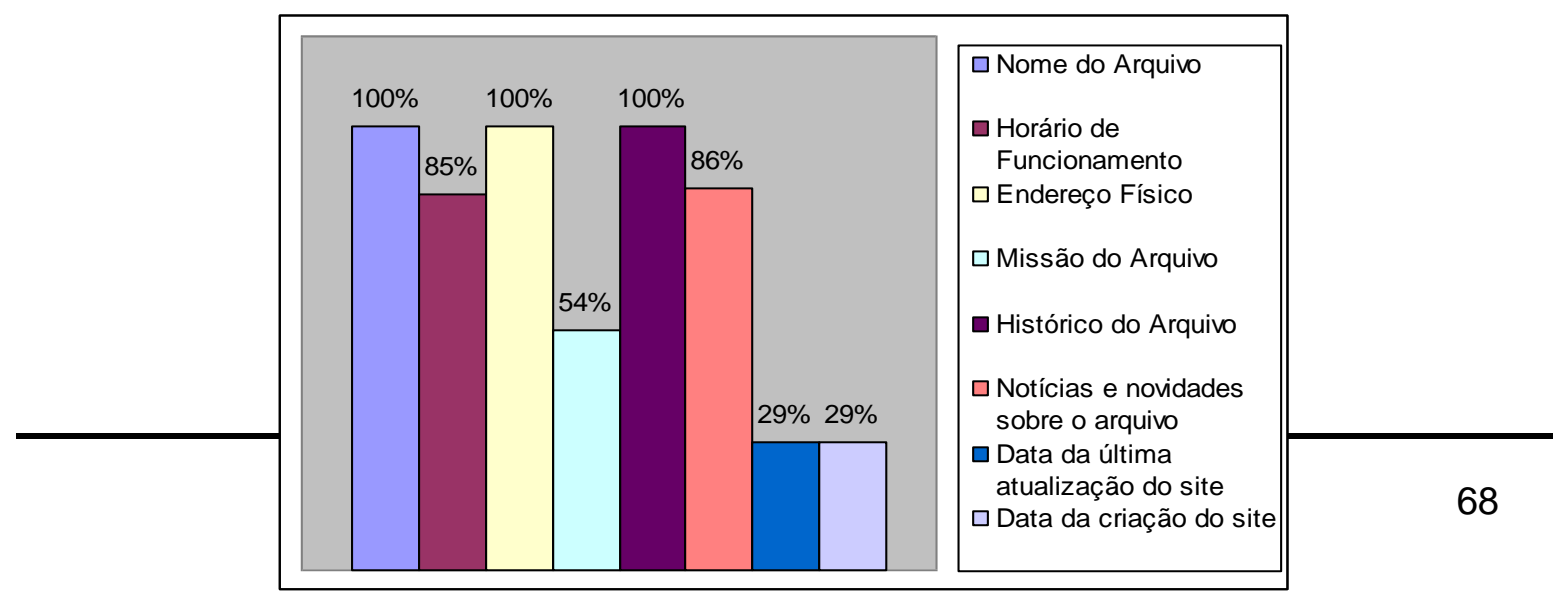




\section{Gráfico 1 Função Informacional nos arquivos públicos brasileiros.}

Esta foi a função mais presente nos sites analisados, estando o nome, o histórico e o endereço físico em 100\% deles, tanto brasileiros quanto estrangeiros. Informações sobre os objetivos do site foram encontradas em $66,5 \%$ dos sites estrangeiros analisados e em nenhum dos sites brasileiros.

Função referencial - apresentação ao usuário das ferramentas que auxiliem na navegação, tais como ferramentas de busca para o conteúdo do site, links para sites de outros arquivos e para publicações eletrônicas de interesse da área.No Brasil, $71 \%$ dos sites de arquivos trazem links para outros arquivos, $64 \%$ apresentam ferramenta para busca interna ao site e $50 \%$ tem links para publicações da área de arquivologia, como pode ser observado no Gráfico 2:

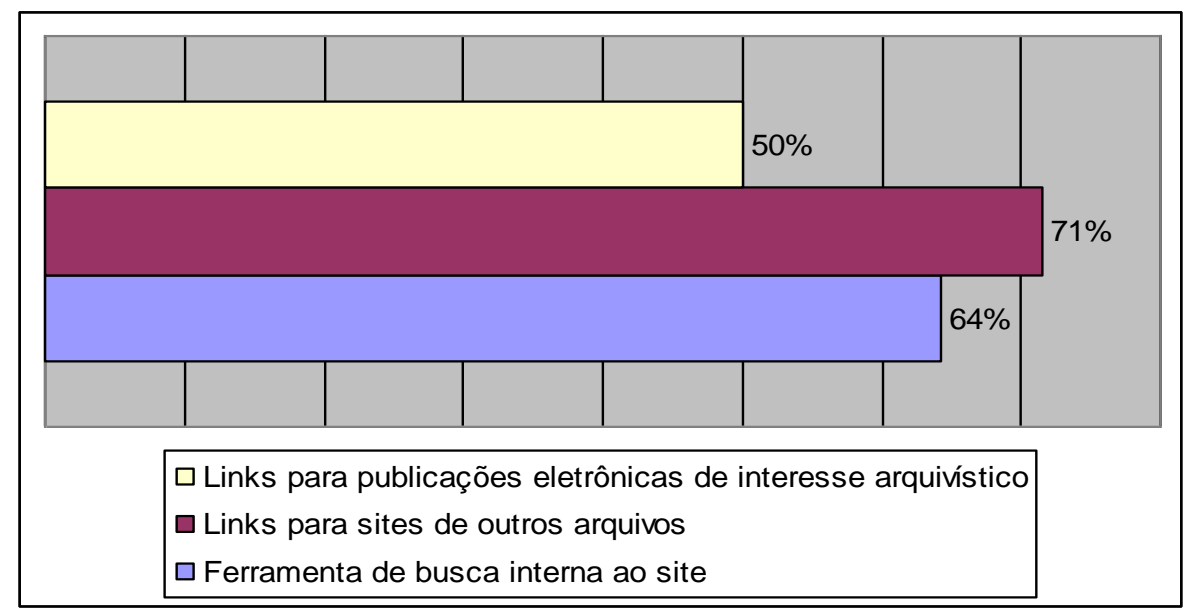

Gráfico 2 Função Referencial nos arquivos públicos brasileiros.

Nos arquivos estrangeiros, $100 \%$ dos sites apresentam ferramenta de busca interna e 66,5\% apresentam links para publicações da área de arquivologia.

Função pesquisa - presença de recursos que auxiliem o usuário em sua busca, como bancos de dados com informações descritivas do acervo, bases de imagem dos documentos, listagens dos serviços oferecidos. Verificou-se que todos os sites têm informações sobre o acervo (100\%), sendo que em $79 \%$ foram encontradas bases de dados somente com descrição arquivística e listagens dos serviços oferecidos, enquanto $50 \%$ apresentam imagem digitais dos documentos, conforme o Gráfico 3. 


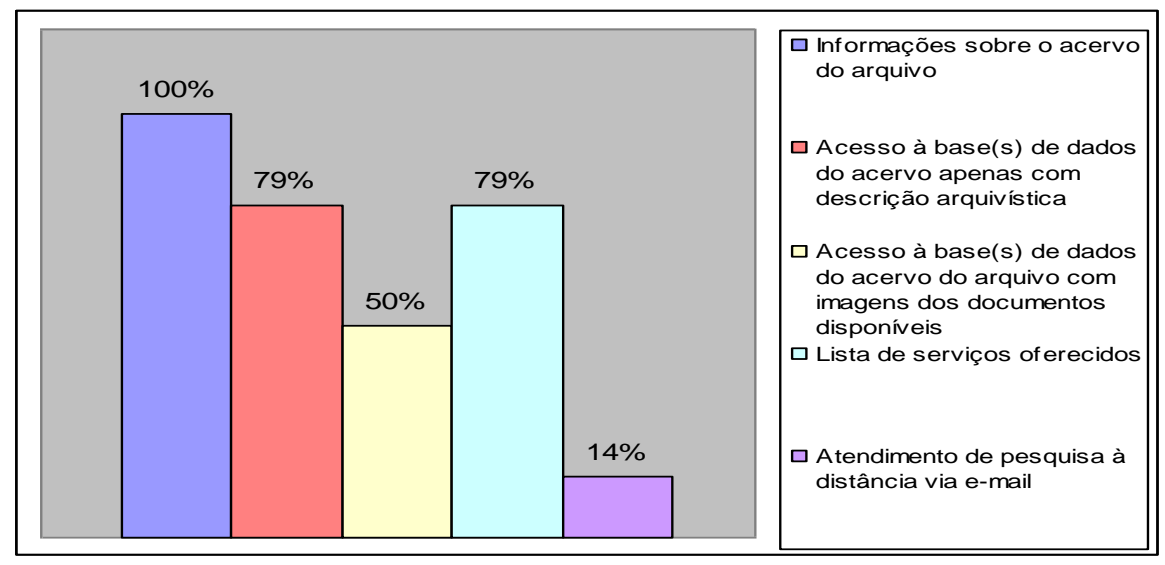

Gráfico 3 Função Pesquisa nos arquivos públicos brasileiros.

Todos os sites estrangeiros $(100 \% 0$ possuem os recursos citados. A disponibilização explícita de contato via e-mail foi encontrada em 14\% dos sites brasileiros e a mensagem instantânea em 33\% dos sites estrangeiros analisados.

Função instrucional - recursos para instruir e guiar o usuário no uso do site ou do arquivo, tais como perguntas frequentes (FAQs), instruções sobre a consulta a bases de dados, mapa do site. Nos sites brasileiros os mais usados são perguntas frequentes (36\%), informações sobre o uso das bases de dados (36\%) e mapa do site (29\%), de acordo com o Gráfico 4:

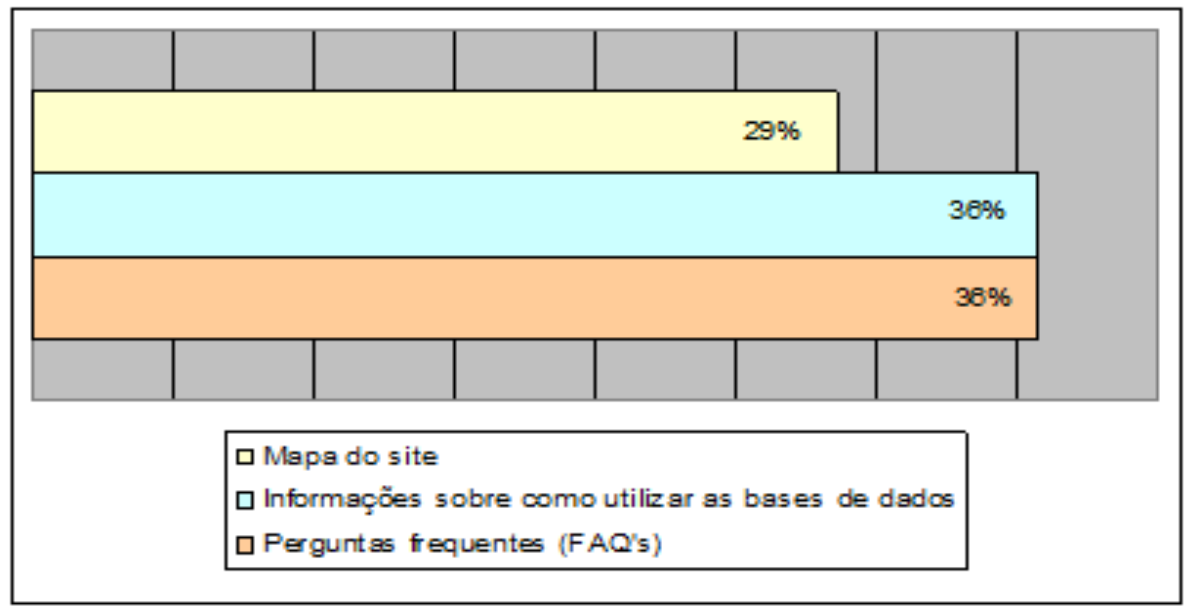

Gráfico 4 Função Instrucional nos arquivos públicos brasileiros. funções.

E $100 \%$ dos sites dos arquivos estrangeiros analisados apresentam estas

Função comunicação - canais para contato com o usuário: números de telefone, cadastro para mala-direta, pesquisa de opinião sobre o site, mensagens instantâneas, vídeos ou links para vídeos sobre o acervo e/ou arquivo. Apenas o telefone e o e-mail são recursos encontrados em 100\% dos sites de arquivos brasileiros. A possibilidade de compartilhamento de vídeos com informações sobre o arquivo ou acervo encontra-se em $29 \%$ dos sites e o cadastramento para mala-direta foi encontrado em $14 \%$ dos sites. $O$ recurso de mensagem 
instantânea como meio de sanar dúvidas dos usuários online não é utilizado, nem enquetes para saber a opinião dos usuários, como demonstra o Gráfico 5:

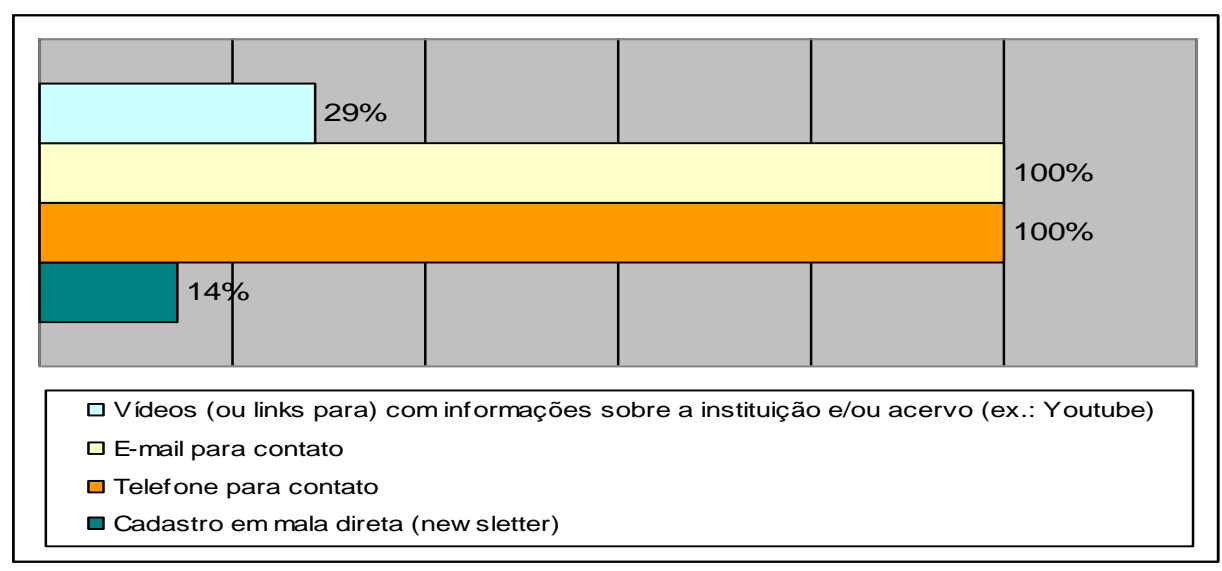

Gráfico 5 Função Comunicação nos arquivos públicos brasileiros.

Nos sites de arquivos estrangeiros analisados, todos os recursos citados são utilizados, sendo que os recursos a seguir estão em apenas um site cada (33\%): cadastro para receber newsletter; pesquisa de opinião do usuário; e mensagens instantâneas para sanar dúvidas.

Função colaboração - utilização de recursos das mídias sociais (web 2.0) nos sites visando possibilitar a participação e colaboração dos usuários, seja incluindo comentários, links e textos em blogs ou wikis, seja utilizando recursos de sites externos para visualização, inclusão, comentários e votação de fotos, vídeos, seja marcando sites favoritos, seja assinando feeds RSS para receber informações sobre atualização das páginas desejadas, ou ainda acrescentando etiquetas (tags). Os recursos web 2.0 ainda são pouco utilizados nos sites de arquivos brasileiros, sendo os mais usados o RSS feed (29\%), seguido de blogs, com permissão para comentários, etiquetas em $21 \%$. Há apenas $7 \%$ dos sites de arquivo com presença em redes sociais, como pode ser observdo no Gráfico 6.

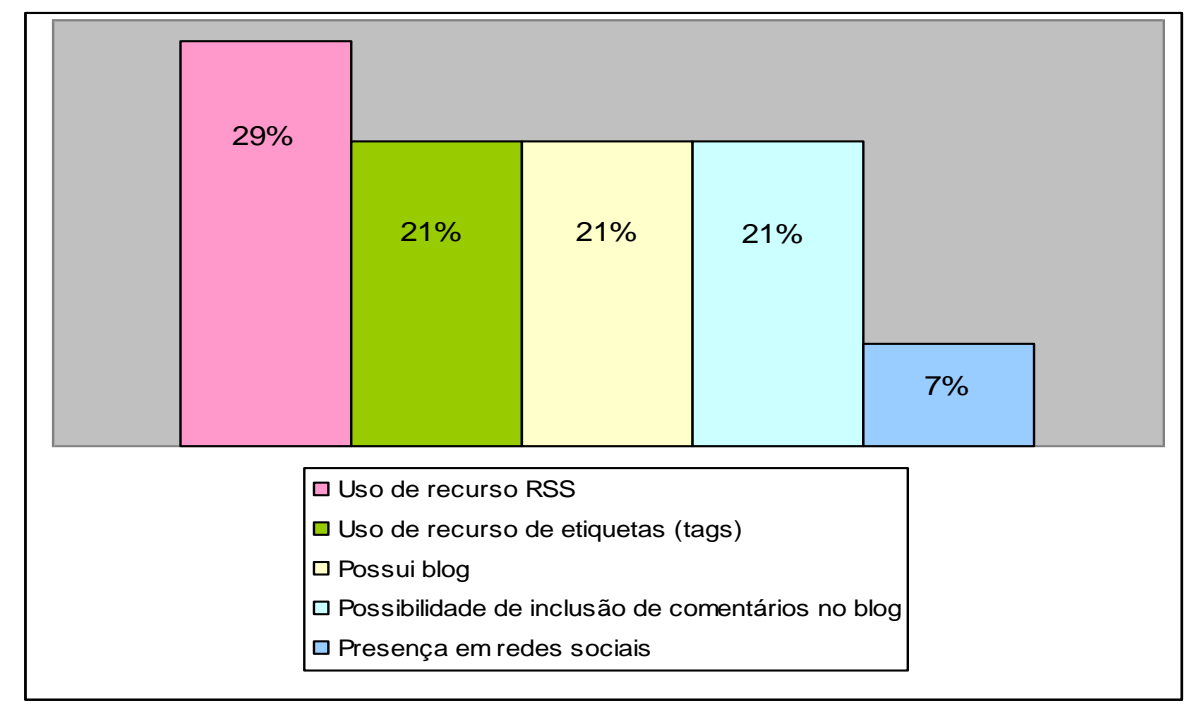

Gráfico 6 Função Colaboração nos arquivos públicos brasileiros. 
Nos sites de arquivos estrangeiros foram encontrados $67 \%$ de arquivos com presença em sites de fotos (como Flickr), sendo que o National Archives, dos Estados Unidos, possui blog com permissão para comentários, Twitter e os demais recursos citados, como RSS feeds. O site do The National Archives do Reino Unido é o único que utiliza wiki.

\section{A VISÃO DOS GESTORES DE ARQUIVOS BRASILEIROS}

Foram enviados questionários aos gestores dos arquivos, visando complementar informações e conhecer a visão dos mesmos sobre a utilização da web como ferramenta de comunicação e colaboração com os usuários. A taxa de retorno dos gestores foi de $70 \%$.

Destes respondentes, $70 \%$ consideraram os websites muito importantes para a instituição, enquanto $15 \%$ o consideram importante e $15 \%$ não responderam a questão. Quanto à existência de controles dos acessos $60 \%$ informaram possuí-los, e destes, $83 \%$ acompanham e controlam os dados disponibilizados através de estatísticas.

A coleta de opiniões e sugestões e informações sobre satisfação e/ou críticas e envio dos dados aos setores responsáveis para sanar dúvidas e verificar problemas dos usuários é feita em $60 \%$ dos arquivos, segundo os respondentes.

Em relação a tornar disponíveis os acervos via web, 90\% prevem fazê-lo, sendo que desses, $56 \%$ a longo prazo, $22 \%$ a médio prazo e $11 \%$ a curto prazo, enquanto $11 \%$ não informaram uma previsão. Já $10 \%$ dos respondentes informaram não prever a disponibilização do acervo na internet por questão de segurança das informações, devido a um grande número de documentos sigilosos.

Das instituições respondentes, 30\% possuem apenas $1 \%$ de seu acervo disponível online e outros 30\% nenhum acervo. 20\% informam que apenas cerca de $0,5 \%$ está online, outros $20 \%$ consideram não ser possível estimar a porcentagem, mas afirmam que é pequena a quantidade de material disponível no site em relação ao acervo que detém.

Em relação aos recursos da web 2.0, 70\% informaram ter intenção de utilizar pelo menos um recurso de colaboração ou interação em no máximo um ano. Entre os recursos apontados por eles, o compartilhamento de vídeos e blogs tiveram $43 \%$ das intenções, seguidos do microbloging - twitter (29\%) e das mensagens instantâneas, redes sociais e RSS feeds, com 11\% das intenções cada.

Todos os gestores respondentes concordaram que existe a necessidade de acompanhamento das mudanças e que a Internet é um meio eficiente e democrático de disponibilizar amplamente o acervo dos respectivos arquivos. Contudo, alguns pontuaram a falta de infraestrutura para a realização de projetos que visem digitalizar os documentos e migrar os instrumentos de pesquisa para 0 formato digital a fim de tornar ágeis as pesquisas, além de preservar a documentação, restringindo ao máximo o manuseio dos documentos. 
Acreditam que a Internet é uma importante aliada na disseminação da informação e divulgação das instituições arquivísticas públicas.

\section{CONSIDERAÇÕES FINAIS}

O estudo exploratório realizado permite observar que as instituições arquivísticas estão longe de aproveitar todo o potencial dos recursos que lhe são disponíveis, contudo tem ciência da necessidade de aplicação dos recursos colaborativos e interativos, a partir do momento em que grande parte dos arquivos prevê a disponibilização de seus acervos, e a utilização de pelo menos algum recurso visando aproximação com os usuários através da Internet.

Cabe lembrar que, no exterior, esse cenário nos arquivos públicos também é recente, por exemplo, o blog do National Archives and Records Administration dos Estados Unidos foi lançado apenas em agosto de 2009. Mas, desde então, houve uma grande mudança em seu portal. Hoje o arquivo americano está trabalhando em uma nova experiência: o Digital Vaults ${ }^{3}$, uma espécie de mosaico digital, que conta a história americana através de imagens de documentos (fotos, cartazes, panfletos, etc), e ainda apresenta conexões entre os fatos históricos, por meio de numa base de dados dinâmica que disponibiliza imagens e documentos históricos a estudantes, pesquisadores, professores e estes ainda podem selecionar as imagens que querem e criar seu próprio "cofre" de imagens.

Os benefícios e a atualidade do uso dos recursos web nos sites de instituições prestadoras de serviços de informação refletiram-se ao longo de toda a pesquisa bibliográfica. Ao comparar a quantidade de artigos publicados pela área biblioteconômica e pela área arquivística, em relação ao tema, uma realidade entristecedora transparece: enquanto a Biblioteconomia se desenvolve acompanhando os avanços tecnológicos, a Arquivologia no Brasil, apesar de contar com uma relativa quantidade de artigos sobre transferência da informação na Internet e meios de acesso aos acervos, ainda não explora o potencial dos recursos 2.0 disponíveis.

A falta de investimento no aprendizado das tecnologias da web por parte das instituições arquivísticas públicas é refletida em seus sites. Deve-se aproveitar a visibilidade institucional que a Internet traz a essas instituições, pois, através dela, pessoas que nunca pensaram em visitar o arquivo podem conhecêlo mesmo estando em outro pais. E os benefícios que esta visibilidade pode trazer aos arquivos públicos são incalculáveis. Com um bom atendimento à distância, maior a quantidade de usuários e, potencialmente, mais recursos tendem a ser revertidos e angariados a fim de atender esta demanda.

Uma Arquivologia contemporânea sintonizada com as mudanças em curso é possível, porém cabe aos profissionais da área, desenvolverem pesquisas e investirem na atualização profissional, a fim de acompanhar os avanços e buscar novos meios de viabilizar a grande função de todo arquivo: guarda responsável e disseminação ampla das informações contidas em seus acervos a quem delas necessita.

\footnotetext{
${ }^{3}$ Endereço : http://www.archives.gov/nae/
} 


\section{REFERÊNCIAS}

AMARAL, Sueli Angélica do. Web Sites: uso de tecnologias no cumprimento das funções da biblioteca. Informação \& Sociedade: Estudos, João Pessoa, v. 15, n. 2, p.15-40, jul. dez. 2005.

BLATTMANN, Ursula, SILVA, Fabiano Couto Corrêa da. Colaboração e interação na web 2.0 e biblioteca 2.0. Revista ACB: Biblioteconomia em Santa Catarina, Florianópolis, v.12, n.2, p.191-215, jul./dez., 2007. Disponível em: <http://www. acbsc.org.br/revista/index.php/racb/article/view/530/664>. Acesso em: 14 maio 2009.

CASTELLS, Manuel. A sociedade em rede. São Paulo: Paz e Terra, 1999.

CUNNINGHAM, Ward. Wiki design principles. 2006. Disponível em: <http://c2.com/cgi/wiki? WikDesignPrinciples> Acesso em: 28 maio 2009.

CONSELHO NACIONAL DE ARQUIVOS. Diretrizes gerais para construção de websites de instituições arquivísticas. Rio de Janeiro: Conarq, 2000.

CORRÊA, Cynthia Harumy Watanabe. Comunidades virtuais gerando identidades na sociedade em rede. Ciberlegenda, 2004. n.13. Disponível em: <http://www. uff.br/mestcii/cyntia1.htm> Acesso em: 28 maio 2009.

JARDIM, José Maria; FONSECA, Maria Odila. Estudos de usuários: em busca de um estado da arte. DataGramaZero: Revista de Ciência da Informação, v. 5, n. 5, out/2004.

LEVÝ, Pierre. A inteligência coletiva: por uma antropologia do ciberespaço. 4. ed. São Paulo: Edições Loyola, 1998.

MANESS, Jack M. Teoria da biblioteca 2.0: web 2.0 e suas implicações para as bibliotecas. Informação \& Sociedade: Estudos, João Pessoa, v. 17, n. 1, p. 44-55, jan/abr. 2007. Disponível em:< www.cipedya.com/doc/102055 >Acesso em: 20 jun. 2009.

MARIZ, Anna Carla Almeida. Arquivos públicos brasileiros: a transferência da informação na Internet. 2005. (Extrato de tese de Doutorado em Ciência da Informação. Instituto Brasileiro de Informação em Ciência e Tecnologia e Universidade Federal do Rio de Janeiro, 2005). Disponível em: < www.asocarchi.cl/DOCS/43.pdf >. Acesso em: 26 mai. 2009.

NEGROPONTE, Nicholas. Being digital. Nova York: Alfred A. Knopf, 1995.

OLIVEIRA, Lucia Maria Velloso de. O usuário como agente no processo de transferência dos conteúdos informacionais arquivísticos. 2006. Dissertação (Mestrado em Ciência da Informação) - Instituto Brasileiro de Informação em Ciência e Tecnologia e Universidade Federal Fluminense, Rio de Janeiro. 
Disponível em: <http://www.bdtd.ndc.uff.br/tde_busca/arquivo.php?codArquivo= 2336>. Acesso em: 07 maio 2009.

\title{
Title
}

Public Archives' Websites: functions and collaborative and interactive resources

\begin{abstract}
This paper analyzes the use of Internet resources websites in public archival institutions from Brazil and other countries. It verifies how Internet resources perform several archival functions such as: information searching, access to collections and support to users through tools for communication and collaboration, including web 2.0 tools. Through a qualitative analysis of websites of archival institutions, it identifies the resources which are available for implementing functions to improve the efficiency of their services to its users. It points out the benefits of these resources and highlights the need of enhancing online communication and collaboration in order to increase the relationship with users. Based on examples from foreign websites, the article underscores the feasibility and features of those resources on archival institutions' websites.
\end{abstract}

\section{Key-words}

Websites. Public Archives. Information Resources.

\section{Título}

Los sitios de los archivos públicos: funciones ejercidas y recursos colaborativos e interactivos con los usuarios

\section{Resumen}

Estudio realizado en los sitios de archivos públicos brasileños y extranjeros, examinando el uso de los recursos de Internet para realizar diversas funciones como la búsqueda de información, el acceso a las colecciones, y el apoyo a los usuarios por medio de herramientas de comunicación y colaboración, incluso las herramientas web 2.0, que dinamizan la participación de los usuarios en un ambiente interactivo y colaborativo. Por medio del análisis cualitativo de los sitios web de las instituciones de archivo, se busco identificar los recursos disponibles para la ejecución de las funciones realizadas por los archivos, especialmente aquellos centrados en la comunicación y colaboración en línea y que pueden mejorar la eficiencia de los servicios prestados a los usuarios. Señala los beneficios potenciales del uso de los recursos de colaboración e interacción con el usuario, destacando la necesidad de apoyo tecnológico por las instituciones de archivo, con el objetivo de ampliar su relación con sus usuarios, la colaboración y el acceso a las colecciones vía Internet. Al presentarse los sitios web extranjeros que utilizan gran parte de los recursos de colaboración, este estudio tiene como objetivo destacar la viabilidad y funcionalidad de la utilización de estos recursos en los sitios web de las instituciones de archivo.

\section{Palabras claves}

Sitios Web. Archivos públicos. Recursos de información. 
Recebido em: 23/08/2010

Aceito em: 11/11/2010 